\title{
EDITORIAL
}

\section{Systems thinking, spirituality and wisdom Perspectives on Ken Wilber}

\section{T} his special issue of Approaching Religion discusses the ideas of an American theoretical psychologist, philosophical thinker and New Age guru, Ken Wilber (b. 1949). Wilber has been described as one of the most influential thinkers of our times, and he exemplifies perfectly the mixture of transpersonal psychology, world philosophy, perennialism, cultural critique, spirituality, business consultancy, and elevated systems thinking that can be found in current forms of spiritual and other sub-cultures.

WILBER PROVIDES MATERIAL for various fields of research and development. For comparative religion, Wilber is a challenge: on one hand, his writings based on idealistic ontology and Buddhism provide an object of study for comparative religion. On the other hand, his views on religion, spirituality and cultural evolution belong in any integral discussion on human nature. In addition, Wilber's integral thinking has been applied in developmental psychology, wisdom research and business consultancy. With this special issue we hope to open some of these themes by using the concepts of systems thinking, spirituality and wisdom as tools.

This special issue stems from a seminar on Ken Wilber held at the Department of Comparative Religion of the University of Turku in the autumn of 2014. The seminar involved Matti Kamppinen and JP Jakonen as facilitators, and 11 students, mostly from the Faculty of Humanities. The students had read Wilber's A Brief History of Everything (Basam Books 2009, translated into Finnish by JP Jakonen) before the seminar, so that the viewpoints of and presentations by the facilitators could be readily and livelily discussed. And indeed, we had fruitful discussions on the concepts of the flatland, systems thinking and spirituality, which crystallized into being the central themes of our Wilber seminar. After the seminar, the students wrote essays (in Finnish) on Wilber. These texts are not published in this issue, but their various themes included the following:

In his essay, Valde Orrenmaa focused on the theory of science and on integral epistemology. $\mathrm{He}$ discussed how Wilber provides tools for a critical appraisal of the one-sided scientism currently prevalent in some cultures. Orrenmaa concluded that Wilber's view of reality is precisely something that is needed in the study of religion, since the object of study denies the flatland of one-dimensional materiality.

Jennina Terho wrote a critical conceptual analysis of the notion of spiritual evolution, and concluded that Wilber has a set of specific idealistic and normative assumptions behind his concept of evolution which sets it far apart from the idea of evolution as it is recognized in science. Terho argued that many of the critical arguments presented by Jeff Meyerhoff in his book Bald Ambition (2010) stand up to philosophical scrutiny and that they point out certain incoherencies and weaknesses in Wilber's thinking.

Anni Rajasto dealt with the notion of the flatland in her essay, tracing its origins in Wilber's writing and its numerous roles in the discourses of postmodern societies. The notion of the flatland was also one of the most discussed and favourite topics of the seminar, since it (or rather its denial) captures at least one of the essential features of spirituality and religious traditions.

Jussi Myyryläinen analysed Wilber's central thoughts in the context of Western esotericism, and argued that Wilber can be justly situated in this long 


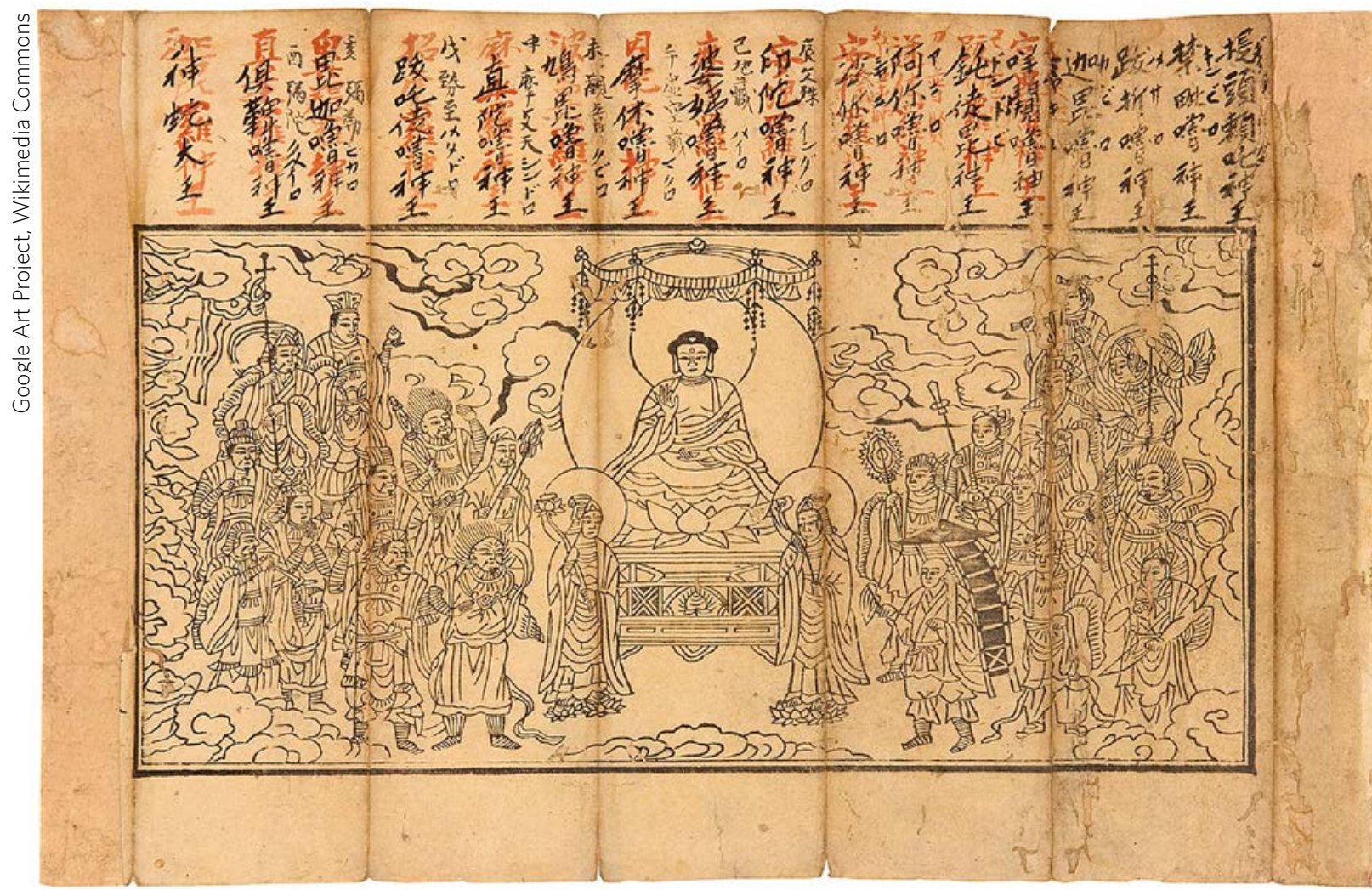

Illustration from Sutra of the Perfection of Wisdom. Fourteenth century, woodcut, ink on paper. Art Gallery of South Australia.

and diverse tradition. A similar point was made by Jukka J. Rintala who discussed Wilber's writings in the context of perennialism, especially in comparison with the ideas of Fritjof Schuon. Again Wilber could be fruitfully situated in the tradition of perennialism, even though he has distanced himself from these traditions. Both Myyryläinen and Rintala presented well-founded arguments to the effect that Wilber is rooted in various traditions, from which he appears to select and discard materials for his own system.

Participants Eero Karhu and Joonas Uotinen took upon themselves the task of writing in English, and their papers are included in this issue. Karhu analysed the current discussions on the material turn in comparative religion and Wilber's possible contribution to the problematic of understanding the material and non-material aspects of religion. Uotinen ventured to deal with the Aristotelian notion of happiness, and how the four quadrants perspective of Wilber's AQAL-model could help in framing the issue of happiness.

In addition to the seminar participants who contributed in writing, the following students took part in discussions: Anna Gradistanac, Niko Virtanen, Kalle Salminen, Petra Rosenberg, Sinikka Kuusela and Tomi Nieminen. We wish to thank all of the stu- dents for making this activity worthwhile, since their fresh perspectives on our fixed views made all the difference.

Before the seminar we had already discussed the idea of creating a special issue of Approaching Religion dealing with Wilber's thinking and were able to invite internationally renowned researchers from different academic fields to contribute to this issue. We are proud to present the articles of Dr Eeva Kallio (developmental psychology), Dr Jorge N. Ferrer (East-West psychology), and Dr Albion Butters (comparative religion, especially Buddhism) in this issue. To complete these perspectives, two contributions by Matti Kamppinen and JP Jakonen are included, as well as the two student papers referred to above, written by Eero Karhu and Joonas Uotinen. Together these contributions provide a package of constructive, sympathetic, explorative and critical viewpoints in understanding Ken Wilber. Not quite an integral assessment, but on the way towards such a view.

MATTI KAMPPINEN \& JP JAKONEN

Guest Editors

RUTH ILLMAN Editor 